Article

\title{
Novel QTL for Stripe Rust Resistance on Chromosomes 4A and 6B in Soft White Winter Wheat Cultivars
}

\author{
Emily F. Klarquist ${ }^{1}$, Xianming M. Chen ${ }^{2}$ and Arron H. Carter ${ }^{3, *}$ \\ Received: 20 November 2015; Accepted: 28 December 2015; Published: 6 January 2016 \\ Academic Editor: Diego Rubiales \\ 1 Department of Crop and Soil Sciences, Washington State University, Pullman, WA 99164-6420, USA; \\ emily.klaruist@wsu.edu \\ 2 USDA-ARS, Wheat Genetics, Physiology, Quality, and Disease Research Unit, and Department of Plant \\ Pathology, Washington State University, Pullman, WA 99164-6430, USA; xianming@wsu.edu \\ 3 Department of Crop and Soil Science, Washington State University, Pullman, WA 99164-6420, USA \\ * Correspondence: ahcarter@wsu.edu; Tel.: +1-509-335-6198; Fax: +1-509-335-8674
}

\begin{abstract}
Stripe rust (caused by Puccinia striiformis f. sp. tritici) of wheat (Triticum aestivum) is a devastating disease in temperate regions when susceptible varieties are grown and environmental conditions sustain high disease pressures. With frequent and severe outbreaks, disease resistance is a key tool for controlling stripe rust on wheat. The goal of this research was to identify quantitative trait loci (QTL) involved in stripe rust resistance from the important US Pacific Northwest soft white winter wheat varieties "Eltan" and "Finch". An F $2: 5$ recombinant inbred line (RIL) mapping population of 151 individuals derived from the Finch $\times$ Eltan cross was developed through single seed descent. A linkage map comprising 683 unique single nucleotide polymorphism (SNP) loci and 70 SSR markers were used to develop 22 linkage groups consisting of 16 of the 21 chromosomes. Stripe rust data were collected on the RILs during the summers of 2012 to 2014. QTL analysis identified two genomic regions on chromosomes $4 \mathrm{~A}(Q Y$ rel.wak- $4 A)$ and $6 \mathrm{~B}(Q Y$ rfi.wak-6B) associated with resistance from Eltan and Finch, respectively. The results of the QTL analysis showed that QYrel.wak-4A and QYrfi.wak-6B reduced infection type and disease severity. Based upon both molecular and phenotypic differences, QYrel.wak-4A is a novel QTL for adult plant resistance (APR) to stripe rust.
\end{abstract}

Keywords: plant breeding; Puccinia striiformis f. sp. tritici; disease resistance; QTL mapping; Triticum aestivum

\section{Introduction}

Wheat (Triticum aestivum L.) is grown on more hectares than any other crop worldwide with an average 80 million hectares of production annually. Hexaploid wheat is highly adaptive to many environments, and having such a vast growing region, wheat is affected by many diseases. Of these pathogens, stripe rust (caused by Puccinia striiformis Westend. f. sp. tritici Erikks.) (Pst) is one of the most destructive and economically significant [1,2]. Major stripe rust epidemics have occurred globally, with losses in some cases amounting to $25 \%[2,3]$.

As a major producer of both spring and winter wheat, the US Pacific Northwest (PNW) has experienced recurrent epidemics. The first of these epidemics occurred in the 1960s, when the PNW experienced several years of stripe rust with significant yield losses of up to 408,000 metric tons in 1961 [4]. The epidemic sparked a new breeding objective for stripe rust resistance in PNW wheat varieties. Since then, wheat breeders in the PNW have looked for new and varying levels of resistance to incorporate into wheat varieties. As a result, most PNW varieties have complex combinations of all-stage and adult-plant resistances that are for the most part uncharacterized. 
Developing a variety with durable resistance can be challenging as resistance is often quantitative in nature, and highly affected by the environment $[1,5,6]$. One type of resistance categorized as all-stage resistance (ASR) is expressed during the full lifecycle of the plant. ASR is easily bred for as these genes are simply inherited and contribute high levels of resistance in varieties at the seedling stage. However, these genes are typically race-specific and are often not durable, being overcome by new virulent races. The second kind of resistance is adult-plant resistance (APR) characterized by varying degrees of resistance expressed at the adult-stage of the plant under high temperatures. APR is typically not race-specific like ASR and is usually associated with durable resistance with some APR genes having been effective for more than 60 years [6]. Although it is not common, $Y r 5$ and $Y r 15$ are a few examples of ASR genes that have remained effective $[7,8]$ in most wheat-growing regions.

A common breeding method in the PNW is to combine various ASR and APR genes into one variety. Resistance genes in combination with one another can give a wheat variety effective broad-spectrum resistance to multiple Pst races [9]. This method of pyramiding resistance genes has been effective for creating durable stripe rust resistance such as that in the PNW multiline variety "Rely" that remains resistant following its release in 1991 through the use of more than 10 different resistance genes [2].

Currently, the most effective methods for disease management are cultural control, fungicide applications and resistance [10], the latter being the most environmentally friendly and cost-effective approach [11]. Cytogenetic and mapping studies to identify resistance in wheat have led to the naming of more than $70 Y r$ genes, but there are many more with temporary designations [12]. The identification and incorporation of $Y r$ genes has significantly benefited wheat growing regions affected by stripe rust. Efforts to develop markers for $Y r$ genes have helped facilitate marker-assisted selection (MAS) and introgression of APR and ASR into elite breeding lines [13,14].

Molecular markers allow breeders to identify and select the presence or absence of genes in early generation populations, and only carry forward material indicative of resistance. These lines are then followed up with disease phenotyping to confirm resistance. They are especially valuable in identifying quantitative traits or screening seedlings for APR resistance [6]. Molecular markers are also valuable when combining APR into a line with ASR, which because of its high level of resistance and continuous expression masks the effect of APR. In addition, MAS can facilitate more lines screened in earlier generations, pyramiding of resistance genes, and potentially reduces the time to release a new variety [15]. By improving the efficiency of disease resistance breeding, MAS may be a key part of increasing wheat production in the future as new Pst races evolve.

In this study, APR resistant varieties Eltan and Finch were chosen to create a recombinant inbred line (RIL) population in order to map quantitative trait loci (QTL) associated with their resistances to stripe rust. Although they have similar stripe rust responses it was previously known that the genetic bases of resistance were different based on race differentiation. The objective of this study was to identify QTL for resistance to stripe rust in Eltan and Finch, and to determine the relative contribution of each. The QTL identified may be useful for incorporating APR into elite breeding lines or varieties by MAS.

Ethical Standards: The experiments conducted during this research are in compliance with the laws of the United States of America.

Key Message: The manuscript describes a novel stripe rust resistance QTL from the cultivar Eltan on the long arm of chromosome $4 \mathrm{~A}(4 \mathrm{AL})$.

\section{Materials and Methods}

\subsection{Plant Materials}

One hundred fifty-one RILs were developed through single seed descent $\left(\mathrm{F}_{2: 5}\right)$. The original cross was made between Finch (PI 628640) and Eltan (PI 536994). Although both parents have APR, it was apparent that the two varieties have different resistance genes based on pedigree and race analysis. 
Finch, a soft white winter wheat, has high yield potential and excellent end use quality [16]. Eltan, also a soft white winter wheat, is high yielding with resistance to snow mold and common bunt, along with good milling and baking properties [17]. Both varieties are adapted to the PNW.

\subsection{Field Experiments}

The RIL population was planted at Central Ferry and Pullman, WA, in 2012, 2013 and 2014. At each location the RILs were grown as two randomized complete blocks with replicated parental checks. Spreaders of highly susceptible line WA7821 were planted around the plot and after every 36 experimental rows. The fields were dependent upon natural infection, except at Pullman in 2014, where a mixture of prevalent races collected from the field in the previous year was used to inoculate spreader rows. Disease ratings at each location commenced when the checks had rust severities of $30 \%$. Infection types (IT) on the expanded 0-9 scale [18,19] and disease severity (DS) from 0 to $100 \%$ [20] were recorded 2 to 3 times per growing season, depending upon environmental conditions and disease levels. The Pullman 2013 and Central Ferry 2014 nurseries were abandoned due to hail damage and insufficient disease, respectively.

\subsection{Statistical Analysis}

Statistical analysis was performed using PROC MIXED in the SAS statistical package (SAS Institute, Raleigh, NC, USA). Least-square mean analysis was used to identify the effects of stripe rust QTL found in the study. Analysis of variance was used to determine genotype $\times$ environment interaction. Lastly, broad-sense heritability of resistance at all locations were calculated using SAS code provided in Holland et al. [21]; $\mathrm{h}^{2}=\operatorname{Var}(\mathrm{G}) / \operatorname{Var}(\mathrm{P})$, where $\operatorname{Var}(\mathrm{G})$ is the genotypic variance and $\operatorname{Var}(\mathrm{P})$ is the phenotypic variance. The final ratings of IT and DS at each location were used for QTL mapping since these scores provided the most discriminatory data.

\subsection{Marker Analysis}

A total of 853 simple sequence repeat (SSR) markers were assayed on the parents, and 88 polymorphic markers were subsequently assayed on the RIL population. Sequences of available SSR markers along with their previously determined chromosomal locations were obtained from Graingenes (http:/ / wheat.pw.usda.gov/). SSR marker analyses were conducted using PCR conditions described by Röder et al. [22] except that primers were synthesized to include the M13-tail [23]. The $10 \mu \mathrm{L}$ reaction mixtures consisted of $50 \mathrm{ng}$ of template DNA, $1.0 \mu \mathrm{L}$ Mg-free $10 \times$ PCR buffer, 0.5 units of Taq DNA polymerase, $1.5 \mathrm{mM}$ of MgCl2 (Promega, Madison, WI, USA), $200 \mu \mathrm{M}$ each of dCTP, dGTP, dTTP, and dATP (Fermentas, Glen Burnie, MD, USA) and $0.25 \mu \mathrm{M}$ of each primer pair synthesized by MWG-Biotech (High Point, NC, USA). Appropriate flourophores for the ABI 3130x1 (Applied Biosystems, Foster City, CA, USA) fragment detection system were included in the PCR mix. Amplification conditions were an initial 5 min denaturation at $94{ }^{\circ} \mathrm{C}$, followed by 41 cycles of $1 \mathrm{~min}$ of denaturation at $94^{\circ} \mathrm{C}, 1 \mathrm{~min}$ of annealing at 50 to $65^{\circ} \mathrm{C}$ (depending on primers), and a 1 min extension at $72{ }^{\circ} \mathrm{C}$. The final extension step was $10 \mathrm{~min}$ at $72^{\circ} \mathrm{C}$.

A total of 8631 SNPs were analyzed on the 9K iSELECT SNP array as described by Cavanagh et al. [24] to identify the genotypes of the RIL population. Genome Studio v2011.1 software (Illumina, San Diego, CA, USA) was used to cluster the SNPs based on genotypes. Minor reassigning of the clusters was done to appropriately call the clusters by their corresponding genotypes. After analysis in Genome Studio v2011.1, 1154 SNP markers and 88 SSR markers were polymorphic between Finch and Eltan. From these, 683 SNP and 70 SSR markers producing robust data were used for mapping. Markers were removed if they had segregation distortion or greater than 10 missing values. Markers which co-segregated at the same locus were removed to enhance the quality of the linkage map constructed for the population in order to identify reliable markers and locations of QTL. Co-segregating markers added back to the linkage map if they associated with a QTL. Upon identification and validation of the 4A QTL, 26 polymorphic SNP markers from the 90K SNP set 
developed by Wang et al. [25] were used as KASP markers (LGC Genomics, Teddington, Middlesex, $\mathrm{UK}$ ), and those from the $9 \mathrm{~K}$ SNP set that failed the chi-squared test were added into the $4 \mathrm{~A}$ linkage group to further saturate the QTL locus.

\section{Linkage Map Construction and QTL Analysis}

A linkage map was constructed with JoinMap 4.0 [26]. Haldane's mapping function was used to calculate genetic distances in centiMorgans $(\mathrm{cM})$ and maximum likelihood mapping algorithm was used to assign linkage groups. Linkage groups were established using a minimum independence LOD score of 3.0. When this LOD value was not able to separate homoeologous chromosomes, a LOD value of 2.0 was used. Each group was assigned to a corresponding chromosome using the previous $9 \mathrm{~K}$ SNP consensus map [24]. QTL analysis was conducted using QTL Cartographer 2.5 [27]. Mapping functions were converted to cM [28]. Composite interval mapping (CIM) analysis with a walk speed of $1.0 \mathrm{cM}$, a window size of $10 \mathrm{cM}$, probability in and out of 0.1 , five control markers, and the forward and backward regression method was used to identify QTL significance. Significant LOD threshold values were determined for each QTL using 1000 permutations at the $0.05 \%$ significance level. Confidence intervals were determined using a one LOD drop-off flanking the peak QTL position [29]. Mapchart version 2.2 [30] was later used to label the QTL on the linkage map.

\subsection{QTL Validation}

In order to validate the QTL, flanking KASP markers (LGC Genomics) were run on some of the previously known varieties containing QTL on chromosomes $4 \mathrm{~A}$ and $6 \mathrm{~B}$ following the standard protocols given by LGC Genomics (lgcgroup.com). The 4A QTL varieties included Avocet S, Heines VII, Nord Desprez, Minister, AUS 91456, Luke, Lalbahadur, and Stephens. Luke did not have an identified 4A QTL but had Nord Desprez in its parentage and was in the pedigree of Eltan. Since the DNA was readily available, Luke was added to the KASP analysis since it could be a possible contributor of resistance QTL in Eltan. Varieties with QTL on chromosome 6B included Stephens, Pavon 76, Recital, Pingyuan 50, and Janz. Unfortunately, seed of additional varieties with QTL reported to be located on chromosome 6B was not available. However, it was apparent that overlapping QTL were present on this chromosome [31].

In addition to KASP markers, the corresponding SSR markers linked to each of the previously identified 4A and 6B QTL were evaluated in Finch and Eltan. Genotyping for 12 SSR markers followed standard protocols with annealing temperatures from GrainGenes 2.0 (http:/ / wheat.pw.usda.gov). Allele lengths were based upon Röder et al. [22] with the addition of $13 \mathrm{bp}$ to account for the fluorescent M13 tails [23]. The SSR markers were run with appropriate flourophores for the ABI 3130xl (Applied Biosystems, Foster City, CA, USA) fragment detection system. The results were analyzed using GeneMarker V1.91 (Soft Genetics, LLC., State College, PA, USA) software.

The Yr51 STS marker sun104, from line AUS 91456, was amplified using the PCR protocol from Randhawa et al. [32]. PCR amplification took place in $12 \mu \mathrm{L}$ volumes containing $2.5 \mathrm{mM}$ dNTP, 25 $\mathrm{mM} \mathrm{MgCl} 2,10 \mu \mathrm{m}$ forward and reverse primer, and $5 \mathrm{U} / \mu \mathrm{L}$ Taq polymerase. This was followed by separation of PCR products in $2.5 \%$ agarose gels with a $1 \mathrm{~kb}$ ladder. A separate SSR marker analysis for Yr60, from variety Lalbahadur [33], using Chinese Spring deletion lines [34] was conducted to determine the location of the recently identified gene in relation to QYrel.wak-4A. Marker analyses were conducted by the USDA Genotyping Laboratory in Pullman, WA, USA.

\section{Results}

\subsection{Field Disease Evaluations}

Annual stripe rust reports collected from the WSU stripe rust website [35] indicated that PSTv-37 was the only race isolated at Central Ferry in 2012, whereas PSTv-37, PSTv-48, and PSTv-11 were isolated at Pullman. In 2013, PSTv-52 was the predominant race at both locations, and continued to 
remain the predominant race in 2014 with PSTv-37 placed second in frequency. In all environments, IT scores for Finch ranged from 3 to 5, those for Eltan ranged from 5 to 8, and the susceptible checks ranged from 8 to 9 . DS ratings averaged 34\% for Finch, $48 \%$ for Eltan, and $>80 \%$ for susceptible checks (data not shown). The RIL population had IT scores from 2 to 8 and DS ranging from as low as $5 \%$ to as high as $87 \%$ across all environments. Both IT and DS data followed normal distributions. Statistical analysis showed that data for both locations were significantly different and that there was a significant interaction between RILs and locations. Broad-sense heritability was 0.49 (standard error $=0.03$ ) for IT and 0.46 (standard error $=0.03$ ) for DS.

\subsection{Linkage Map Construction}

A total of 1154 SNP and 88 SSR markers were polymorphic between Finch and Eltan. From these, 683 SNP and 70 SSR markers were used in constructing the linkage map. The 683 SNPs represented unique loci and the 471 SNP markers not used cosegregated at the mapped loci, had $>10$ missing values, or did not fit 1:1 segregation ratios. For ease of analysis, only one SNP marker was used to represent each locus. If a locus was identified as significantly associated with stripe rust resistance, cosegregating markers were added back into the linkage map. These markers established 22 linkage groups representing 16 of the 21 wheat chromosomes $(2 \mathrm{D}, 3 \mathrm{D}, 4 \mathrm{D}, 5 \mathrm{D}$ and $6 \mathrm{D}$ chromosomes were not represented). The map covered a total of $2051 \mathrm{cM}$ with an average distance of $3.3 \mathrm{cM}$ between markers on each chromosome. The $\mathrm{D}$ genome had noticeably lower coverage with five of the seven chromosomes not represented in the linkage map. Low levels of polymorphism in the D genome are often obtained in linkage map construction.

\subsection{QTL Identification}

Two Pst resistance QTL were identified. The first QTL on chromosome 6BL, designated QYrfi.wak-6B and contributed by Finch, was effective at Pullman 2012 and 2014 and Central Ferry 2013. The highest phenotypic variation explained across all environments amounted to $31 \%$ for IT and $15 \%$ for DS (Table 1). The QTL spanned an average $41.3 \mathrm{cM}$ region with a peak position at $46 \mathrm{cM}$ and significant markers Xiwa6599, Xiwa5170, and Xiwa4202 at 44, 45, and $46 \mathrm{cM}$, respectively (Figure 1). A second QTL, designated QYrel.wak-4A and contributed by Eltan, was identified on chromosome 4AL at Pullman 2012, Central Ferry 2012 and 2013, and Pullman 2014 and explained up to 17\% of the phenotypic variation for IT and up to $16 \%$ for DS (Table 1). The QTL spanned $37 \mathrm{cM}$ with a peak position at $98 \mathrm{cM}$ and significant markers Xiwa1692, Xiwa1720, Xiwa5200, and Xiwa6885 at 114, 113, 113, and $102 \mathrm{cM}$, respectively (Figure 1). The positions of these markers on the $9 \mathrm{~K}$ wheat SNP consensus map are located between 97 and $103 \mathrm{cM}$, with the exclusion of Xiwa6885 which is not listed on the consensus map due to low levels of polymorphisms in the tested germplasm [24]. Further evaluation of markers from the 90K SNP set identified Xiwb58791 linked to this QYrel.wak-4A also. This QTL was significant in all three years of the study but failed to significantly reduce DS in Pullman 2012 and IT in Pullman 2013. Across all significant locations, DS and IT were reduced by $8 \%$ and $10 \%$, respectively, among the RILs carrying the QYrel.wak-4A QTL.

Disease scores associated with specific genotypes were evaluated in SAS to determine the QTL genetic effect on response. As shown in Figure 2, IT scores and DS for the RILs carrying the Eltan allele at QYrel.wak- $4 A$ were reduced by $10 \%$ and $8 \%$, respectively, compared to lines carrying neither resistance QTL. RILs containing the Finch allele at QYrfi.wak-6B also showed a significant reduction of the IT score of $10 \%$ but had no significant reduction in DS compared to lines carrying neither QTL. When both QTL were present, IT scores were significantly reduced by an average of $22 \%$ and DS was reduced by $14 \%$ compared to lines without either QTL. These results show an additive effect of the two QTL when combined. 
Table 1. Quantitative trait loci (QTL) identified in the Finch $\times$ Eltan winter wheat recombinant inbred line mapping population for infection type (IT) and disease severity (DS) of stripe rust in Pullman (PU) and Central Ferry (CF), WA, across three years.

\begin{tabular}{|c|c|c|c|c|c|c|c|c|c|c|}
\hline QTL & Trait & Year & Location & cM Peak & Confidence Interval & Nearest Marker & LOD & $R^{2}$ & Additive Effect & Parent \\
\hline \multirow[t]{6}{*}{ QYrel.wak- $4 A$} & IT & 2012 & PU & 98.9 & $94.2-103.3$ & Xiwa6885 & 6.09 & 0.14 & 0.64 & \multirow[t]{6}{*}{ Eltan } \\
\hline & & & $\mathrm{CF}$ & 97 & $90.8-112.2$ & Xiwa6885 & 8.73 & 0.17 & 1.12 & \\
\hline & & & $\mathrm{CF}$ & 99.8 & $96.6-101.9$ & Xiwa6885 & 3.01 & 0.05 & 0.96 & \\
\hline & IT & 2013 & CF & 90.8 & 81-101.2 & Xiwa6193/Xiwa2606 & 3.51 & 0.09 & 0.65 & \\
\hline & DS & 2013 & $\mathrm{CF}$ & 83 & $78.8-101.7$ & Xiwa6193/Xiwa2606 & 5.19 & 0.16 & 10.1 & \\
\hline & IT & 2014 & PU & 94 & 78.6-101.7 & Xiwa6193/Xiwa2606 & 3.94 & 0.09 & 0.55 & \\
\hline \multirow[t]{5}{*}{ QYrfi.wak-6B } & IT & 2012 & PU & 40.7 & $30.9-90$ & Xiwa6599 & 7.21 & 0.31 & 1.41 & \multirow[t]{5}{*}{ Finch } \\
\hline & & 2013 & $\mathrm{CF}$ & 46.2 & $32.8-68.6$ & Xiwa6599 & 5.34 & 0.15 & 0.91 & \\
\hline & & 2014 & PU & 46.4 & $33.4-68.6$ & Xiwa6599 & 4.46 & 0.12 & 0.47 & \\
\hline & DS & 2012 & PU & 45.2 & $32.9-78.1$ & Xiwa6599 & 5.00 & 0.15 & 5.62 & \\
\hline & & 2013 & CF & 46.2 & $33.4-63.7$ & Xiwa6599 & 3.94 & 0.10 & 7.44 & \\
\hline
\end{tabular}


$4 \mathrm{~A}$

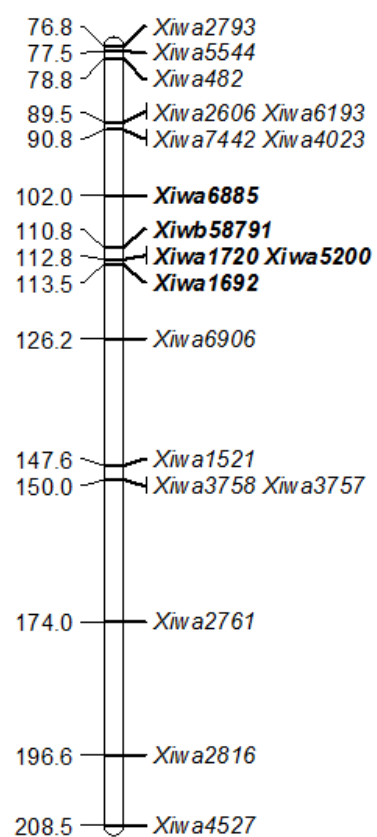

6B

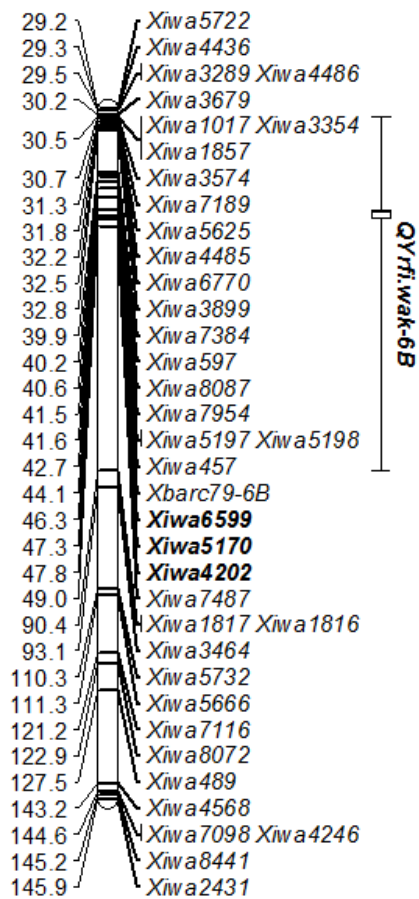

Figure 1. Quantitative trait loci (QTL) maps for QYrel.wak-4A and QYrfi.wak-6B in the Finch $\times$ Eltan recombinant inbred line mapping population. Markers in bold are associated with the respective QTL and were used to determine novelty of QTL in other germplasm.

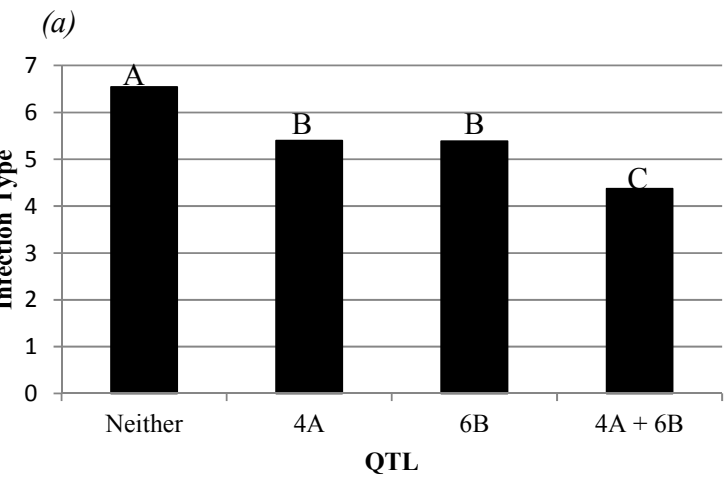

(b)

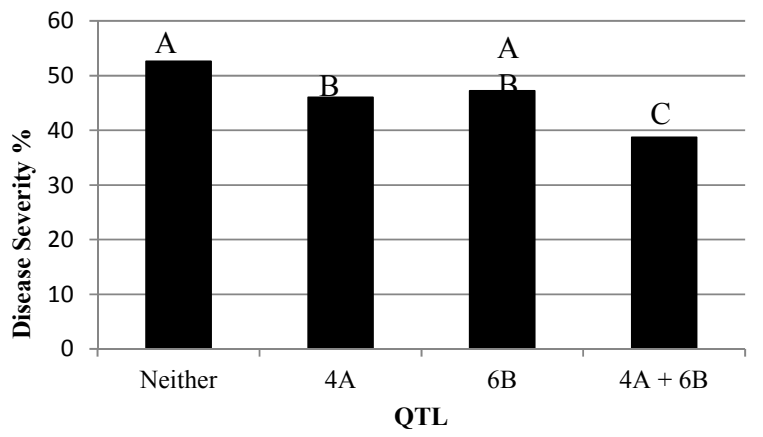

Figure 2. Infection type (a) and disease severity (b) ratings across all environments for the Finch $\times$ Eltan recombinant inbred line population for those lines containing both stripe rust quantitative trait loci (QTL), only the 4A QTL, only the 6B QTL, and neither. 


\subsection{QTL Comparisons}

In an effort to try and distinguish the identified QTL from other QTL and named genes reports on the same chromosome, markers were analyzed for comparison with other varieties carrying previously reported QTL and those found in Finch and Eltan. Although the identified SNP markers are only linked to the QTL and not fully diagnostic of presence/absence of the QTL, they do assist in providing further insight between the relationship of varieties carrying different QTL based on observed haplotypes. KASP markers for the SNPs associated with the 6B QTL were evaluated on accessions with similar QTL locations that found in the RIL population (Table 2). Once converted to KASP markers, only two of the three originally polymorphic SNP markers (Xiwa5170 and Xiwa6599) amplified in Finch. Almost all varieties with previously identified 6B QTL matched one of the two KASP markers with Finch, whereas Pavon 76 was heterozygous at both marker loci. The 6B KASP allele at Xiwa5170 in Finch was shared among Stephens, Janz, Pingyuan 50 and Recital, whereas the Finch Xiwa6599 was unique to that variety.

Table 2. (a) KASP markers associated with QYrel.wak-4A from Eltan as compared to varieties containing previously reported 4A quantitative trait loci (QTL); (b) KASP markers associated with QYrfi.wak-6B from Finch as compared to varieties containing previously reported 6B QTL.

\begin{tabular}{cccccccc}
\hline \multirow{2}{*}{ Variety } & \multicolumn{3}{c}{ QYrel.wak-4A Markers } & \multicolumn{3}{c}{ QYrfi.wak-6B Markers } \\
\cline { 2 - 7 } & Xiwwa5200 & Xiwwa1720 & Xiwa6885 & Xiwa1692 & Xiwa5170 & Xiwa6599 \\
\hline Finch & C & A & C & C & G & T \\
Eltan & T & G & T & T & A & C \\
Stephen & C & A & C & C & G & C \\
Avocet & C & A & T & C & - & - \\
Heines VII & C & A & T & T & - & - \\
Nord Deprez & C & A & C & T & - & - \\
Minister & C & A & T & C & - & - \\
AUS91456 & T & G & T & C & - & - \\
Luke & T & A/G & C/T & C & - & - \\
Recital & - & - & - & - & G & C \\
Janz & - & - & - & - & G & C \\
Pingyuan 50 & - & - & - & - & G & C \\
Pavon 76 & - & - & - & - & A/G & C/T \\
\hline
\end{tabular}

When available, SSR markers for varieties previously identified to have stripe rust QTL on chromosome 6B were evaluated on Finch to further differentiate QYrfi.wak-6B from previously discovered genes and QTL (Table 3). The previously reported QTL identified in Stephens [36] was on the same chromosome as the Finch QTL. When SSR marker Xbarc101 was run on Finch and Eltan, both parents were negative for the Stephens resistance allele. These results match a previous paper from Uauy et al. [37]. Additionally, to confirm that QYrfi.wak-6B was not $Y r 36$ (another gene found in this region), the Xuhw89 marker [13] was run on both parents in which both were found negative in having the Yr36 allele. For the other QTL found on this chromosome, varieties Pavon 76, Pingyuan 50, and Recital QTL had no alleles in common with Finch.

Seven other varieties reported to have QTL on chromosome 4A were evaluated with the SNP markers associated with QYrel.wak-4A (Table 2a). At 4A marker Xiwa5200, only varieties AUS 91456 and Luke shared the resistance allele with Eltan. The cosegregating marker Xiwa1720 was present only AUS 91456. For marker Xiwa6885, varieties Avocet S, Heines VII, Minister, and AUS 91456 shared the resistance allele with Eltan, whereas with marker, Xiwa1692, none of the varieties carried the resistance allele, although Heines VII and Nord Desprez were heterozygous at this locus. No variety shared the same resistance haplotype across the four SNP markers with Eltan. 
Table 3. SSR markers for varieties with a known $4 \mathrm{~A}$ or $6 \mathrm{~B}$ stripe rust quantitative trait loci (QTL) assayed on Finch and Eltan to determine if either had the positive (+) allele length for that varieties resistant QTL.

\begin{tabular}{|c|c|c|c|c|c|c|}
\hline Chromosome & Marker & Finch & Eltan & Variety & $\begin{array}{c}\text { Repeat } \\
\text { Length bp }\end{array}$ & Source \\
\hline $6 \mathrm{~B}$ & Xgwm58 & - & - & Pavon76 & 133 & Williams et al. [38] \\
\hline $6 \mathrm{~B}$ & Xbarc136 & - & - & Stephens & 280 & Santra et al. [36] \\
\hline $6 \mathrm{~B}$ & Xgwm193 & - & - & Renan & $-\mathrm{a}$ & Dedryver et al. [39] \\
\hline $6 \mathrm{~B}$ & $X g d m 113$ & - & - & Stephens & 163 & Santra et al. [36] \\
\hline $6 \mathrm{~B}$ & Xbarc101 & - & - & Stephens & 185 & Santra et al. [36] \\
\hline $6 \mathrm{~B}$ & Xgwm626 & + & - & Pavon 76 & 101 & Williams et al. [38] \\
\hline $6 \mathrm{~B}$ & Xgwm132 & + & + & Stephens & 118 & Santra et al. [36] \\
\hline $6 \mathrm{~B}$ & Xgwm136 & - & - & Pingyuan 50 & 275 & Lan et al. [40] \\
\hline $6 \mathrm{~B}$ & Xgwm361 & - & - & Pingyuan 50 & 123 & Lan et al. [40] \\
\hline $6 \mathrm{~B}$ & Xuhw89 & - & - & T. turgidum spp. dicoccodes & 124 & $\begin{array}{c}\text { Uauy et al. [37] } \\
\text { Ramburan et al. [41] }\end{array}$ \\
\hline $4 \mathrm{~A}$ & Xgwm160 & - & - & Avocet/IDO444 (Kariega) & 209 & Chen et al. [42] \\
\hline $4 \mathrm{~A}$ & Xbarc70 & + & - & Stephens & 247 & Vazquez et al. [43] \\
\hline
\end{tabular}

SSR markers for varieties with previously described 4A resistance QTL were also evaluated in Eltan to determine presence of similar QTL to QYrel.wak-4A (Table 3). Heines VII, Minister, and Nord Desprez did not have markers associated with their reported $Y_{r}$ genes. Chromosome 4A SSR markers were available only for QTL in Stephens, Avocet S, and IDO444. Vazquez et al. [43] identified multiple APR QTL in Stephens with one identified on 4A by linkage to SSR marker Xbarc70; Eltan did not share that allele [31]. The 4A QTL from IDO444, described by Chen et al. [42], was found at a similar location to a QTL in Kariega [41]. These two varieties and Avocet S share a common allele at Xgwm160. Neither Finch nor Eltan shared the allele with Avocet $\mathrm{S}$ and consequently did not share it with either Kariega or IDO444. Table 4 further identifies known genes on chromosome $4 \mathrm{~A}$ and further describes their location and resistance type as compared to Qyrel.wak-4A.

Table 4. Varieties containing stripe rust genes/ quantitative trait loci (QTL) on chromosome 4A. The resistance type APR (adult plant resistance) or AS (all stage resistance). Gene/QTL name and location are listed for each of the varieties.

\begin{tabular}{ccccc}
\hline Variety & Gene/QTL & Resistance Type ${ }^{\text {a }}$ & Location (cM) & Source \\
\hline Heines VII & YrHVII & ASR & Location unknown & Chen et al. [44] \\
Minister & YrMin & ASR & Location unknown & Chen et al. [44] \\
Nord Deprez & YrND & ASR & Location unknown & Chen et al. [44] \\
Stephens & Qyrst.orr-4AL & APR & 44.8 & Vazquez et al. [43] \\
AUS91456 & Yr51 & ASR & 104.6 & Randhawa et al. [32] \\
IDO444 & Qyrid.ui-4A & APR & Long arm & Chen et al. [42] \\
Lalbahadur & Yr60 & ASR & Distal end of 4AL & Herrera-Foessel et al. [33] \\
Kariega & QYr.sgi-4A1 & Early field resistance only & Long arm & Ramburan et al. [41] \\
Avocet S & QYr.sgi-4A2 & Identified in a growth & Long arm & Ramburan et al. [41] \\
\hline
\end{tabular}

${ }^{\text {a }}$ ASR = All-stage resistance; APR = Adult-plant resistance.

Since two additional genes for stripe rust resistance have been reported on chromosome $4 \mathrm{AL}$ in wheat, markers were analyzed to determine if QYrel.wak-4A was the same as either Yr51 or Yr60. Based on marker analysis using sun104 for $Y r 51$, no amplification of the diagnostic $225 \mathrm{bp}$ allele associated with this gene was present in Eltan (data not shown). To further distinguish QYrel.wak-4A from Yr51 and $Y r 60$, Chinese Spring 4A deletion lines were used to demonstrate that these genes are located in different deletion bins (Table 5). The genes $Y r 51$ and $Y_{r} 60$ are reported to be $10 \mathrm{cM}$ from each other on the distal end of chromosome 4AL. Using the 4AS deletion series (with a fully intact 4AL arm), the diagnostic alleles for markers corresponding to $Y_{r 51}$ and $Y_{r 60}$ were present, indicating these genes 
reside on chromosome $4 \mathrm{AL}$. Analysis of the $4 \mathrm{AL}$ deletion series found no diagnostic alleles, indicating that these genes reside at the distal end of 4AL. Of the four SNP markers associated with QYrel.wak-4A, only two of the designed KASP assays (Xiwa5200 and Xiwa1692) amplified in Chinese Spring. Analysis of the 4AS deletion series demonstrated presence of the SNP, again indicating that these markers were present on $4 \mathrm{AL}$. In the $4 \mathrm{AL}$ deletion series, these two SNP markers were always present, indicating that their location resides between the centromere and breakpoint 0.43 . This is further supported by the location of these SNPs on the IWGSC chromosome-based draft sequence of wheat [45]. These markers are located at 116 to $122 \mathrm{cM}$ on $4 \mathrm{AL}$, an estimated $38 \mathrm{cM}$ from the centromere [45].

Table 5. Chinese Spring deletion lines for $4 \mathrm{AL}$ and $4 \mathrm{AS}$ were evaluated with SSR markers from Yr60 variety "Lalbahadur" and KASP markers for QYrel.wak- $4 A$ to determine the location of the two loci on the long arm of chromosome $4 \mathrm{~A}$.

\begin{tabular}{cccccc}
\hline \multirow{2}{*}{ Variety } & \multicolumn{3}{c}{ Yr60 SSR Markers (bp) } & \multicolumn{2}{c}{ QYrel.wak-4A KASP } \\
\cline { 2 - 6 } & Xwmc776 & Xwmc219 & Xwmc313 & Xiwa5200 $^{\text {a }}$ & Xiwa1692 \\
\hline Chinese & 226 & 222 & 215 & + & + \\
Spring & & & & & \\
4AS 0-0.2 c & 226 & 222 & 215 & + & + \\
4AS 0-0.63 & 226 & 222 & 215 & + & + \\
4AS 0-0.76 & 226 & 222 & 215 & + & + \\
4AS 0-1.0 & 226 & 222 & 215 & + & + \\
\hline 4AL 0-0.43 & - & - & - & + & + \\
4AL 0-0.66 & - & - & - & + & + \\
4AL 0-0.73 & - & - & - & + & + \\
4AL 0-0.79 & - & - & - & + & + \\
4AL 0-0.82 & - & - & - & + & + \\
4AL 0-0.85 & - & - & - & + & + \\
4AL 0-1.0 & 226 & 222 & 215 & + & + \\
\hline
\end{tabular}

a KASP markers for Xiwa6885 and Xiwa1720 did not amplify in the Chinese Spring control line and subsequent deletion lines; ${ }^{\mathrm{b}} \mathrm{A}$ " + " indicates presence of the allele, whereas a "-" indicates absence of the allele; ${ }^{\mathrm{c}}$ Designation includes chromosome number and short (S) or long (L) arm designation as well as the breakpoint interval from the centromere to the distal end of the respective arm.

\section{Discussion}

Resistance is a key management tool for controlling stripe rust. Especially in growing regions where chemical control is not economically justifiable, stripe rust resistant wheat varieties are usually the only effective option for growers [12]. By identifying novel genes for stripe rust resistance, breeders can incorporate those genes into breeding material by MAS to reduce the disease severity. Molecular markers genetically linked to a stripe rust resistance QTL or genes can be used by breeders to efficiently and accurately incorporate resistance into new germplasm. In the Finch $\times$ Eltan RIL population, we have presented two QTL which can be selected via molecular markers to incorporate resistance into wheat varieties. The lack of polymorphisms in the D genome in this population, which is not uncommon [46,47], did not allow us to analyze much of the D genome for resistance loci. Therefore, there may be additional QTL from these cultivars that we were not able to identify with the SNP system used. We have submitted this population for genotyping-by-sequencing, which allows for better coverage of the D genome [48] and will allow discovery of QTL on this genome if present.

Even though the identified QTL are of minor effect, they should be useful when pyramided together with other stripe rust resistance genes or QTL. The 6B marker results indicated that QYrfi.wak-6B is not found in the five lines tested with other germplasm carrying QTL on 6B and may be a novel QTL for Pst resistance. The 4A QTL QYrel.wak-4A was also tested in other germplasm to see if this locus had been reported previously. Based on race differentiation, displayed phenotype, marker analysis, and physical location using deletion lines, QYrel.wak- $4 A$ appears to be a novel locus. Although both QYrel.wak- $4 A$ and QYrfi.wak-6B only contribute to decreases in IT by $10 \%$ individually, when 
pyramided together, they decreased IT by $20 \%$. A similar trend was seen with DS, with pyramided QTL decreasing severity by $14 \%$. Thus, it appears that individually, these QTL appear as minor QTL, but when pyramided together produce an additive effect.

Even though these QTL appear to be novel, more research is needed to confirm this. Currently, it has been difficult to compare the chromosomal location of QYrel.wak- $4 A$ and QYrfi.wak- $6 B$ with previously identified stripe rust QTL due to differences in marker platforms and associated linkage maps. Our SNP derived linkage map has 70 SSR markers positioned on it, resulting from a screen of over 850 markers. This was not enough to compare chromosomes $4 \mathrm{~A}$ and $6 \mathrm{~B}$ to other published SSR maps due to lack of similar markers. As marker platforms continue to evolve, and more linkage maps are published with a combination of SSR and SNP markers, the ability to compare these maps with other consensus maps will be possible. The projection of these QTL regions on other consensus maps should allow better estimations of QTL positions in the near future. Additionally, to further distinguish QYrel.wak-4A and QYrfi.wak-6B from other published QTL, we are introgressing these QTL into Avocet $S$ to validate the effect of these QTL on race composition and ability to reduce IT and DS.

The additive nature of these two QTL indicate pyramiding with other genes will be effective at providing resistance to stripe rust, and the novelty of the QTL will provide wheat breeders with additional genes to pyramid in combination with already used sources of resistance. It should be noted though that based on field testing, the APR resistance in Eltan appears to be responsive to different races. QYrel.wak-4A was effective against predominant races in the Palouse area (PSTv-37 and PSTv-11), and was considered resistant to stripe rust. In 2012, a new race, PSTv-52 was identified and has since become the most abundant race in the PNW, but Eltan is only considered to be moderately susceptible-susceptible to this race [49]. Most reported APR genes are stable across environments, years, and races $[31,37,50]$. Greenhouse studies are being conducted with different races to differentiate the effect of race structure on this APR QTL.

For pyramiding of genes to be effective, especially those of minor effect or when combining ASR and APR together, effective molecular markers need to be identified. Few stripe rust resistance genes have been cloned with perfect molecular markers [51]. Previously, single SSR markers, or flanking markers, were sufficient to determine presence or absence of a linked locus [31]. Now, with the use of SNP markers for genotyping and linkage map development, single SNP markers linked to QTL are likely not effective to fully distinguish presence or absence of a linked QTL. SNP haplotypes more fully represent presence or absence of a particular linked gene or QTL. The markers reported in this study effectively distinguish presence/absence when used in combination with the bolded markers presented (Figure 1). Additionally, these markers are fairly easy to run and analyze using SNP or KASP marker systems, and will allow most breeders to effectively select for these loci.

\section{Conclusions}

Two QTL for stripe rust APR identified in this study significantly reduced DS and IT in winter wheat varieties Eltan and Finch. Analysis showed that no previously identified 4A Pst resistance QTL were similar to the one described in this study. Furthermore, most QTL or genes described in previous literature contributed to all-stage resistance and/or were in a different location on 4AL. The lines carrying QYrel.wak-4A had reductions in DS of $6.6 \%$ and of $10 \%$ for IT in 2012. The reduced LOD score and phenotypic variation explained by the QTL in 2013 and 2014 indicate that the effectiveness of the APR in Eltan was reduced by the new race PSTv-52. However, the PSTv-52 race is avirulent to QYrfi.wak-6B, the QTL contributed by Finch, which is still effective at reducing disease incidence in winter wheat for the Pacific Northwest and other wheat growing regions. There were only two SNP markers associated with QYrfi.wak-6B; in order to provide more diagnostic markers, fine mapping of the QTL region will be needed. The additive effects of these QTL together increased resistance significantly and are beneficial in combination for reducing stripe rust infection in winter wheat varieties. With the moderate levels of heritability and a quarter of the phenotypic variation explained 
across environments, efforts to pyramid these QTL into elite breeding lines will be advantageous and feasible.

Acknowledgments: We thank Gary Shelton, Adrienne Burke, and Yukiko Naruoka for assistance in maintaining field plots, DNA markers, and assistance with disease ratings. This project was funded in part by Washington State University (Project \#0232), the Washington Grain Commission (project \#3672), and the National Research Initiative Competitive Grants CAP project 2011-68002-30029 from the United States Department of Agriculture National Institute of Food and Agriculture.

Author Contributions: E.F.K. constructed the linkage map and performed the KASP experiments. E.F.K. and A.H.C. carried out the data analysis and interpretation and wrote the paper. X.M.C. edited the paper, assisted in field data collection, and supplied regional stripe rust data.

Conflicts of Interest: The authors declare no conflict of interest.

\section{References}

1. Chen, X.M. Epidemiology and control of stripe rust [Puccinia striiformis f. sp. tritici] on wheat. Can. J. Plant Path. 2005, 27, 314-337. [CrossRef]

2. Wellings, C.R. Global status of stripe rust: A review of historical and current threats. Euphytica 2011, 179, 129-141. [CrossRef]

3. Chen, X.M. Challenges and solutions for stripe rust control in the United States. Aust. J. Agric. Res. 2007, 58, 648-655. [CrossRef]

4. Line, R.F. Stripe rust of wheat and barley in North America: A retrospective historical review. Annu. Rev. Phytopathol. 2002, 40, 75-118. [CrossRef] [PubMed]

5. Qayoum, A.; Line, R.F. High-temperature, adult-plant resistance to stripe rust of wheat. Phytopathology 1985, 75, 1121-1125. [CrossRef]

6. Chen, X.M. Review Article: High-temperature adult-plant resistance, key for sustainable control of stripe rust. Am. J. Plant Sci. 2013, 4, 608-627. [CrossRef]

7. Gerechter-Amitai, Z.K.; van Silfout, C.H.; Grama, A.; Kleitman, F. Yr15 a new gene for resistance to Puccinia strifformis in Triticum dicoccoides sel. G-25. Euphytica 1989, 43, 187-190. [CrossRef]

8. Wan, A.; Chen, X.M. Virulence characterization of Puccinia striiformis f. sp. tritici using a new set of $Y r$ single-gene line differentials in the United States in 2010. Plant Dis. 2014, 98, 1534-1542.

9. Campbell, M.A.; Fitzgerald, H.A.; Ronald, P.C. Engineering pathogen resistance in crop plants. Transgen. Res. 2002, 11, 599-613. [CrossRef]

10. Roelfs, A.P.; Singh, R.P.; Saar, E.E. Rust Diseases of Wheat: Concepts and Methods of Disease Management; CIMMYT: Mexico, D.F., Mexico, 1992; pp. 1-81.

11. McIntosh, R.A.; Wellings, R.A.; Park, R.F. Wheat Rusts: An Atlas of Resistance Genes; CSIRO Publications: East Melbourne, VIC, Australia, 1995; pp. 20-26.

12. McIntosh, R.A.; Yamazaki, Y.; Dubcovsky, J.; Rogers, J.; Morris, C.; Appels, R.; Xia, X.C. Catalogue of Gene Symbols for Wheat. In Proceedings of the 12th International Wheat Genetics Symposium, Yokohama, Japan, 8 September 2013; Springer: Tokyo, Japan, 2015.

13. Distelfeld, A.; Uauy, C.; Fahima, T.; Dubcovsky, J. Physical map of the wheat high-grain protein content gene Gpc-B1 and development of a high-throughput molecular marker. New Phytol. 2006, 169, 753-763. [CrossRef] [PubMed]

14. Murphy, L.R.; Santra, D.; Kidwell, K.; Yan, G.Y.; Chen, X.M.; Campbell, K.G. Linkage maps of wheat stripe rust resistance genes $Y r 5$ and $Y r 15$ for use in marker-assisted selection. Crop Sci. 2009, 49, 1786-1790. [CrossRef]

15. Collard, B.C.Y.; Mackill, D.J. Marker-assisted selection: An approach for precision plant breeding in the twenty-first century. Philos. Trans. R. Soc. B 2008, 303, 557-572. [CrossRef] [PubMed]

16. Campbell, K.G.; Allan, R.E.; Anderson, J.; Pritchett, J.A.; Little, L.M.; Morris, C.F.; Line, R.F.; Chen, X.; Walker-Simmons, M.K.; Carter, B.P.; Burns, J.W.; Jones, S.S.; Reisenauer, P.E. Registration of “Finch" Wheat. Crop Sci. 2005, 45, 1656-1657. [CrossRef]

17. Peterson, C.J.; Allan, R.E. Registration of “Eltan" Wheat. Crop Sci. 1991, 31, 1704. [CrossRef]

18. McNeal, F.H.; Konzak, C.F.; Smith, E.P.; Tate, W.S.; Russell, T.S. A Uniform System for Recording and Processing Cereal Research Data; USDA-ARS: Washington, DC, USA, 1971; pp. 34-121. 
19. Line, R.F.; Qayoum, A. Virulence, Aggressiveness, Evolution, and Distribution of Races of Puccinia Striiformis (the Cause of Stripe Rust of Wheat) in North America, 1968-1987; U.S. Department of Agriculture Technical Bulletin No. 1788; National Technical Information Service: Springfield, VA, USA; February; 1992; p. 44.

20. Peterson, R.F.; Campbell, A.B.; Hannah, A.E. A diagrammatic scale for estimating rust intensity on leaves and stems of cereals. Can. J. Res. 1948, 26, 496-500. [CrossRef]

21. Holland, J.B.; Nyquist, W.E.; Cervantes-Martinez, C.T. Estimating and interpreting heritability for plant breeding: An update. In Plant Breeding Reviews; Janick, J., Ed.; John Wiley \& Sons, Inc.: Hoboken, NJ, USA, 2003; Volume 22.

22. Röder, M.S.; Korzun, V.; Wendehake, K.; Plaschke, J.; Tixier, M.; Leroy, P.; Ganal, W. (1998) A microsatellite map of wheat. Genetics 1998, 149, 2007-2023.

23. Oetting, W.S.; Lee, H.K.; Flanders, D.J.; Wiesner, T.A.; Sellers, T.A.; King, R.A. Linkage analysis with multiplexed short tandem repeat polymorphisms using infrared fluorescence and M13 tailed primers. Genomics 1995, 30, 450-458. [CrossRef] [PubMed]

24. Cavanagh, C.; Chao, S.; Wang, S.; Huang, B.E.; Stephen, S.; Kiani, S.; Forrest, K.; Saintenac, C.; Brown-Guedira, G.; Akhunova, A.; et al. Genome-wide comparative diversity multiple targets of selection for improvement in hexaploid wheat landraces and cultivars. Proc. Natl. Acad. Sci. USA 2013, 110, 8057-8062. [CrossRef] [PubMed]

25. Wang, S.; Wong, D.; Forrest, K.; Allen, A.; Chao, S.; Huang, B.; Maccafern, M.; Salvi, S.; Milner, S.; Cattivelli, L.; et al. Characterization of polyploid wheat genomic diversity using a high-density 90,000 single nucleotide polymorphism array. Plant Biotechnol. J. 2014, 12, 787-796. [CrossRef] [PubMed]

26. Van Ooijen, J.W. JoinMap 4, Software for Calculation of Genetic Linkage Maps in Experimental Populations; Kyazma B.V.: Wageningen, The Netherlands, 2006.

27. Basten, J.C.; Weir, B.S.; Zeng, Z.B. Windows QTL Cartographer 2.5; North Carolina State University, Department of Statistics: Raleigh, NC, USA, 2012.

28. Kosambi, D. The estimation of map distances from recombination values. Ann. Eugen. 1943, 12, $172-175$. [CrossRef]

29. Chaky, J.M. Advanced Backcross QTL Analysis in a Mating Between Glycine max and Glycine soja. Master's Thesis, University of Nebraska, Lincoln, NE, USA, 2003.

30. Voorrips, R.E. MapChart: Software for the graphical presentation of linkage maps and QTLs. J. Hered. 2002, 93, 77-78. [CrossRef] [PubMed]

31. Rosewarne, G.; Herrera-Foessel, S.A.; Singh, R.P.; Huerto-Espino, J.; Lan, C.X.; He, Z.H. Quantitative trait loci for stripe rust resistance in wheat. Theor. Appl. Genet. 2013, 126, 2427-2449. [CrossRef] [PubMed]

32. Randhawa, M.; Bansal, U.; Valárik, M.; Klocová, B.; Doležel, J.; Bariana, H. Molecular mapping of stripe rust resistance gene Yr51 in chromosome 4AL of wheat. Theor. Appl. Genet. 2014, 127, 317-324. [CrossRef] [PubMed]

33. Herrera-Foessel, S.A.; Singh, R.P.; Lan, C.X.; Huerta-Espina, J.; Calvo-Salazar, V.; Bansal, U.K.; Bariana, H.S.; Lagudah, E.S. Yr60, a gene conferring moderate resistance to stripe rust in wheat. Plant Dis. 2015, 99, 508-511. [CrossRef]

34. Endo, T.R.; Gill, B.S. The deletion stocks of common wheat. J. Hered. 1996, 87, 295-307. [CrossRef]

35. Annual Stripe Rust Race Data Reports. Available online: http:/ / striperust.wsu.edu/races/stripe-rust-racedata.html (accessed on 26 October 2015).

36. Santra, D.K.; Chen, X.M.; Santra, M.; Campbell, K.G.; Kidwell, K.K. Identification and mapping QTL for high-temperature adult-plant resistance to stripe rust in winter wheat (Triticum aestivum L.) cultivar "Stephens". Theor. Appl. Genet. 2008, 117, 793-802. [CrossRef] [PubMed]

37. Uauy, C.; Brevis, J.; Chen, X.; Khan, I.; Jackson, L.; Chicaiza, O.; Distelfeld, A.; Fahima, T.; Dubcovsky, J. High-temperature adult-plant (HTAP) stripe rust resistance gene $Y_{r} 36$ from Triticum turgidum ssp. dicoccoides is closely linked to the grain protein content gene Gpc-B1. Theor. Appl. Genet. 2005, 112, 97-105. [PubMed]

38. Williams, H.M.; Singh, R.P.; Huerta-Espino, J.; Palacios, G.; Suenaga, K. Characterization of genetic loci conferring adult plant resistance to leaf rust and stripe rust in spring wheat. Genome 2006, 49, 977-990. [CrossRef] [PubMed]

39. Dedryver, F.; Paillard, S.; Mallard, S.; Robert, O.; Trottet, M.; Nègre, S.; Verplancke, G.; Jahier, J. Characterization of genetic components involved in durable resistance to stripe rust in the bread wheat "Renan". Phytopathology 2009, 99, 968-973. [CrossRef] [PubMed] 
40. Lan, C.; Liang, S.; Zhou, X.; Zhou, G.; Lu, Q.; Xia, X.; He, Z. Identification of genomic regions controlling adult-plant stripe rust resistance in Chinese landrace Pingyuan 50 through bulked segregant analysis. Phytopathology 2010, 100, 313-318. [CrossRef] [PubMed]

41. Ramburan, V.P.; Pretorius, Z.A.; Louw, J.H.; Boyd, L.A.; Smith, P.H.; Boshoff, W.H.P.; Prins, R. A genetic analysis of adult plant resistance to stripe rust in the wheat cultivar Kariega. Theor. Appl. Genet. 2004, 108, 1426-1433. [CrossRef] [PubMed]

42. Chen, J.; Chu, C.; Souza, E.; Guttieri, M.; Chen, X.; Xu, S.; Hole, D.; Zemetra, R. Genome-wide identification of QTL conferring high-temperature adult-plant (HTAP) resistance to stripe rust (Puccinia striiformis $\mathrm{f}$. sp. tritici) in wheat. Mol. Breed. 2011, 29, 791-800. [CrossRef]

43. Vazquez, M.D.; Peterson, C.J.; Riera-Lizarazu, O.; Chen, X.; Heesacker, A.; Ammar, K.; Crossa, J.; Mundt, C.C. Genetic analysis of adult plant, quantitative resistance to stripe rust in wheat cultivar "Stephens" in multi-environment trials. Theor. Appl. Genet. 2012, 124, 1-11. [CrossRef] [PubMed]

44. Chen, X.M.; Line, R.F.; Jones, S.S. Chromosomal locations of genes for resistance to Puccinia striiformis in winter wheat cultivars Heines VII, Clement, Moro, Tres and Daws. Phytopathology 1995, 85, 1362-1367. [CrossRef]

45. IWGSC. A chromosome-based draft sequence of the hexaploid bread wheat (Triticum aestivum) genome. Science 2014, 345, 286.

46. Neumann, K.; Kobiljski, B.; Dencic, S.; Varshney, R.K.; Börner, A. Genome-wide association mapping: A case study in bread wheat (Triticum aestivum L.). Mol. Breed. 2011, 27, 37-58. [CrossRef]

47. Zegeye, H.; Rasheed, A.; Makdis, F.; Badebo, A.; Ogbonnaya, F.C. Genome-wide association mapping for seedling and adult plant resistance to stripe rust in synthetic hexaploid wheat. PLoS ONE 2014, 9, e105593. [CrossRef] [PubMed]

48. Poland, J.A.; Brown, P.J.; Sorrells, M.E.; Jannick, J-L. Development of high-density genetic maps for barley and wheat using a novel two-enzyme genotyping-by-sequencing approach. PLOS ONE 2012, 7, e32253. [CrossRef] [PubMed]

49. Chen, X.M.; (USDA-ARS Research Plant Pathologist, Pullman, WA, USA). Personal communication, 2015.

50. Carter, A.H.; Chen, X.M.; Garland-Campbell, K.; Kidwell, K.K. Identifying QTL for high temperature adult-plant resistance to stripe rust (Puccinia striiformis f. sp. tritici) in the spring wheat (Triticum aestivum L.) cultivar "Louise". Theor. Appl. Genet. 2009, 119, 1119-1128. [PubMed]

51. Fu, D.; Uauy, C.; Distelfeld, A.; Blechl, A.; Epstein, L.; Chen, X.; Sela, H.; Fahima, T.; Dubcovsky, J. A kinase-START gene confers temperature-dependent resistance to wheat stripe rust. Science 2009, 323, 1357-1360. [CrossRef] [PubMed]

(C) 2016 by the authors; licensee MDPI, Basel, Switzerland. This article is an open access article distributed under the terms and conditions of the Creative Commons by Attribution (CC-BY) license (http://creativecommons.org/licenses/by/4.0/). 